Ekonomia - Wroclaw Economic Review 22/1 (2016)

Acta Universitatis Wratislaviensis

No 3731

DOI: $10.19195 / 2084-4093.22 .1 .2$

\author{
Mariusz Maziarz \\ Uniwersytet Ekonomiczny we Wrocławiu \\ mariusz.maziarz@ue.wroc.pl
}

\title{
Wspólnotowe społeczeństwa a wzrost gospodarczy. Mechanizmy oddziaływania
}

\author{
JEL Classification: O15, O43, O52
}

Keywords: collectivism, individualism, economic development, causal mechanism

\begin{abstract}
Community Societies and Economic Growth. Mechanisms of Influence

Recent econometric research showed that there is a positive correlation between collectivism of a society and economic development. In this article, I aim at analyzing the causal mechanisms that connect this dimension of culture and economic efficiency. On the base of the conducted meta-analysis of questionnaires, case studies and other empirical research, I coined the following four possible causal mechanisms that make economies of collectivist-oriented societies grow faster: (1) more efficient business relations among economic agents; (2) rarer egoistic behaviours; (3) increased security due to belonging to a group and (4) positive influence on innovativeness.
\end{abstract}

\section{Wstęp}

Zainteresowanie ekonomistów tematyką kulturowych uwarunkowań biznesu międzynarodowego oraz wpływu cech charakteryzujących społeczeństwa na rozwój gospodarczy zostało zapoczątkowane przez Webera (1904), jednak systematyczne badania poświęcone temu zagadnieniu zostały podjęte dopiero po publikacji książki Culture’s Consequences (Hofstede 1980), której autor wyszczególnił (początkowo) cztery wymiary kultury: dystans do władzy, indywidualizm-kolektywizm, kobiecość-męskość i unikanie niepewności, oraz opracował sposoby ich mierzenia na podstawie analizy wyników badania ankietowego przeprowadzonego wśród pracowników IBM.

Dotychczasowe badania ekonometryczne wskazują na istnienie pozytywnego związku pomiędzy jednym z wymiarów kultury wyróżnionych przez Geerta

Ekonomia - Wroclaw Economic Review 22/1 (2016)

(C) for this edition by CNS 
Hofstedego, indywidualizmem-kolektywizmem, a rozwojem ekonomicznym. Dla przykładu, Maziarz (2015) przedstawił model estymowany dla danych opisujących gospodarki i społeczeństwa krajów Unii Europejskiej, wskazując, iż to nie społeczeństwa indywidualistyczne, lecz wspólnotowe notowały szybszy wzrost gospodarczy. Zorientowanie społeczeństw na wartości wspólnotowe może przyczyniać się nie tylko do wzrostu średniego tempa rozwoju ekonomicznego, lecz również prowadzić do wzrostu bardziej zrównoważonego (por. Czerniak 2012).

Celem artykułu jest dokonanie analizy mechanizmów, które powodują, że gospodarki krajów, których społeczeństwa są zorientowane wspólnotowo, rozwijają się szybciej, co pozwoli stwierdzić, czy obserwowana w badaniach ekonometrycznych zależność ma charakter relacji przyczynowej, w której wspólnotowość powoduje szybszy rozwój gospodarczy, czy wynika z przypadkowej korelacji lub istnienia wspólnych determinant orientacji społeczeństwa na wspólnoty oraz tempa rozwoju gospodarczego.

\section{Teoretyczny aspekt badań}

Smith w przełomowym dziele $O$ bogactwie narodów (2007, księga 4, rozdział 2) pisał, że przedsiębiorca, który usiłuje zmaksymalizować zysk, jest prowadzony przez niewidzialną rękę do efektywnego wyniku, który nie był zamierzony. Pomimo pojawiających się w literaturze przedmiotu głosów o wpływie czynników kulturowych na tempo wzrostu gospodarczego już na początku XX wieku (np.: Weber 1904) oraz możliwości wystąpienia problemu koordynacji, gdzie indywidualistyczne zachowania nie prowadzą do optymalnego rezultatu, podobnie jak w sformułowanym przez Flooda i Dreshera tzw. dylemacie więźnia (Marks 2004: 54), kwestia wpływu poziomu indywidualizmu na wzrost gospodarczy nie była rozpatrywana. Przełomem okazała się publikacja Hofstedego (1980: 8), który wstępnie wyróżnił cztery wymiary kultury: dystans do władzy; indywidualizm-kolektywizm; kobiecość-męskość; unikanie niepewności.

Co oznacza pojęcie ,indywidualizm”? Dołęgowski (2012) definiuje to pojęcie jako system wartości, „w którym jednostka występuje jako wyłączony podmiot własnych decyzji, niekrępowanych przez jakikolwiek autorytet, wspólnotę czy władzę publiczną". Green et al. (2005) wskazują na powiązanie indywidualizmu z wartościami niezależności, samodzielności, unikatowości, osiągnięć, konkurencji oraz odpowiedzialności za swoje zachowania. Wspólnotowość lub kolektywizm (ang. collectivism; w polskiej literaturze występują oba określenia) jest to nazwa ukuta na określenie społeczeństw, w których przeważa: świadomość wspólnotowa, identyfikacja z grupą i solidarność z jej członkami, zależność emocjonalna, potrzeba stabilizacji, równe dzielenie się przywilejami i obowiązkami i grupowe podejmowanie decyzji (Knack, Keefer 1997). Chen i West (2008) podkreślają wagę przywiązywaną przez członków społeczeństwa wspól- 
notowego do jedności z innymi, zorientowania na relacje, poczucia połączenia z innymi oraz relacje interpersonalne. Podobnie Tiessen (1997) wskazuje na bezkonfliktowość wewnątrz grup i harmonijną współpracę jako cechy społeczeństw wspólnotowych.

Mimo iż w literaturze przedmiotu można znaleźć odmienne ujęcia (por. Allik, Realo 2004; Wagner 2002), indywidualizm w badaniach ekonomicznych jest najczęściej stawiany w opozycji do wspólnotowości/kolektywizmu. Za takim ujęciem przemawiają dwa argumenty. Po pierwsze, dotychczas skonstruowane miary ujmujące indywidualizm i wspólnotowość nie jako przeciwieństwa, lecz odrębne konstrukty nie zostały wykorzystane do mierzenia poziomu indywidualizmu i wspólnotowości na dużą skalę, co uniemożliwia zastosowanie tak osiągniętych wyników w badaniach ekonometrycznych. Po drugie, porównanie definicji indywidualizmu i kolektywizmu wskazuje na przeciwieństwo tych wymiarów kultury. Za takim punktem widzenia opowiada się większość ekonomistów (np. Hofstede 1980) oraz socjologów (Diener et al. 2000) zajmujących się problemem związków pomiędzy kulturą społeczeństwa a efektywnością gospodarowania.

Pomimo ukazania się Culture's Consequences (Hofstede 1980) jeszcze w latach 80 . XX wieku pokutował pogląd, że wzrost gospodarczy jest silnie związany z egoistycznymi zachowaniami jednostek, które — zgodnie z poglądami Smitha - kierują się wyłącznie maksymalizacją zysku. Peterson (1980: 69-70) wskazywał, że nasilenie w społeczeństwie wartości przeciwnych do indywidualizmu, czyli wartości wspólnotowych, jest negatywne dla wzrostu gospodarczego, ponieważ chęć spełnienia swojej potrzeby przynależności prowadzi do odwrócenia ludzi od orientacji na osiągnięcia (McClelland 1976). Podobne wnioski przedstawił również Hofstede (1991: 76).

Podejście ekonomistów do wpływu indywidualizmu na zachowania pracowników i ich wpływ na tempo wzrostu gospodarczego zaczęły się zmieniać na początku lat 90., czego przykładem może być artykuł Kellnera (1994) opublikowany w „Sunday Times”, w którym autor stwierdza, że niskie tempo wzrostu gospodarczego w Wielkiej Brytanii jest związane z wysokim poziomem indywidualizmu pracowników. Na poparcie swojej tezy autor przytacza statystykę korelacji tempa wzrostu PKB i poziomu indywidualizmu, która jest silnie ujemna $(\mathrm{r}=-0,67)$ dla 18 najbardziej uprzemysłowionych państw świata. Swank (1996) na podstawie prowadzonych badań ekonometrycznych stwierdził, że model oparty na zmiennych opisujących kapitał ludzki, tempo konwergencji oraz - co ważne z punktu widzenia problemów poruszanych w artykule - natężenie wartości wspólnotowych wyjaśnia $84 \%$ różnic w tempie wzrostu gospodarczego 25 krajów na przestrzeni od 1960 do 1989 roku. Ponadto, Ostrom (1990) argumentowała za tezą, że dobra wspólne mogą być efektywnie zarządzane poprzez stowarzyszenie, wspólnotę użytkowników. Natomiast Putnam (2013: 253) napisał, iż jedną z przyczyn, dlaczego niektóre gospodarki są obecnie wysoko rozwinięte, jest zorientowanie społeczeństw na wspólnoty: „Te społeczeństwa nie stały się wspólnotowe tylko 
dlatego, że są bogate. Zapis historyczny sugeruje odwrotną zależność: one zostały bogate, ponieważ były wspólnotowe".

Pozytywny wpływ wartości wspólnotowych na rozwój ekonomiczny został również zaobserwowany przez polskich ekonomistów. Czerniak (2012) na podstawie badań ekonometrycznych dochodzi do wniosku, iż gospodarki państw, których społeczeństwa są wspólnotowe, charakteryzują się większą odpornością na kryzysy ekonomiczne. Mianowicie, kraje takie notują mniejsze zróżnicowanie stóp wzrostu gospodarczego. Maziarz (2015), na podstawie badania ekonometrycznego polegającego na zbadaniu wpływu indywidualizmu/kolektywizmu na tempo rozwoju ekonomicznego państw Unii Europejskiej poprzez kontrolowanie wpływu innych determinant za pomocą modelu Barro (1996), wskazuje, iż tempo rozwoju ekonomicznego jest pozytywnie skorelowane ze zorientowaniem społeczeństwa na wspólnoty.

Obserwacje Kellnera zostały poparte wyjaśnieniami zaproponowanymi przez Adamsa i Ruiz-Ulloa (2003), którzy, prowadząc analizę komparatystyczną przedsiębiorstw w Indiach oraz Irlandii, zauważyli, że wysoki poziom indywidualizmu wśród pracowników może przyczyniać się do zróżnicowania celów indywidualnych i grupowych oraz utrudnia komunikację. W wyróżnionym przez Hofstedego (1980) wymiarze kultury indywidualizm/wspólnotowość przeciwieństwem indywidualizmu jest uznanie społeczeństwa dla wartości wspólnotowych. Taki sam punkt widzenia na kwestię przeciwstawności kolektywizmu i wspólnotowości prezentuje Diener et al. (2000), którzy opracowali alternatywną miarę siły zorientowania społeczeństw na wspólnoty.

W ostatnich latach coraz więcej ekonomistów wskazuje na istnienie związku pomiędzy orientacją na wartości wspólnotowe, tj.: poczucie obowiązku w stosunku do grupy, zależności od innych, pragnienie harmonii społecznej oraz przestrzeganie norm przyjętych przez grupę (Green et al. 2005) a stabilniejszym i szybszym wzrostem gospodarczym (Siewierski 2012; Maziarz 2015), jednak mechanizmy oddziaływania analizowanego w artykule wymiaru kultury na gospodarkę nie zostały dotychczas zbadane w wystarczającym stopniu.

\section{Metodologia badań}

Jak zauważono, dotychczasowe badania wskazują na istnienie statystycznie istotnej zależności pomiędzy zorientowaniem społeczeństwa na wspólnoty a szybszym rozwojem ekonomicznym. Celem niniejszego artykułu jest wskazanie potencjalnych mechanizmów przyczynowych łączących cechy społeczeństw kolektywistycznych i wzrostu gospodarczego. Aby go zrealizować, dokonano przeglądu wybranej literatury poświęconej empirycznej analizie związków między przejawami wspólnotowego zorientowania społeczeństw a efektywnością ekonomiczną. 


\section{Mechanizmy przyczynowe}

Na podstawie przeprowadzonej metaanalizy wyszczególniono cztery mechanizmy przyczynowe, które mogą powodować istnienie obserwowanego w badaniach ekonometrycznych związku pomiędzy zorientowaniem społeczeństwa na wspólnoty i tempem rozwoju ekonomicznego. Po pierwsze, w kulturach kolektywistycznych relacje między podmiotami ekonomicznymi lub pracodawcą i pracownikiem są silniejsze i trwają dłużej. Po drugie, w przeciwieństwie do społeczeństw indywidualistycznych zorientowanie na wspólnoty przyczynia się do ograniczenia zachowań egoistycznych, rzadszego łamania norm prawnych oraz większej stabilności relacji biznesowych. Po trzecie, silne wspólnoty, przez zapewnienie stabilności i bezpieczeństwa, odciążają system finansowy państwa dobrobytu. Po czwarte, orientacja społeczeństwa na grupy może sprzyjać wdrażaniu innowacji. Dalej opisano wyniki doświadczeń i obserwacji świadczące na rzecz istnienia tych mechanizmów przyczynowych.

\subsection{Zwiększenie efektywności relacji pomiędzy podmiotami ekonomicznymi}

Zgodnie z przytoczonymi definicjami i przejawami zorientowania społeczeństwa na wspólnoty taka orientacja społeczeństwa wyraża się poprzez świadomość jedności z innymi ludźmi i orientację na relacje. W związku z tym można przypuszczać, że ludzie wywodzący się z takiej kultury nie będą przejawiać transakcyjnego podejścia do biznesu, tj. kierować się wyłącznie racją zysku.

Dzięki identyfikacji członków grupy z jej celami, poczuciu jedności z innymi ludźmi (Chen, West 2008) osoby wychowane w społeczeństwach wspólnotowych będą wykazywać więcej starań i motywacji w dążeniach do realizacji zaplanowanych zadań. W związku z takim przypuszczeniem Ramamoorthy et al. (2007) dokonali analizy studium przypadku zaangażowania pracowników w firmach działających w dwóch społeczeństwach charakteryzujących się odmiennym poziomem orientacji na wspólnoty.

Pracownicy pochodzący z Irlandii, których cechuje kultura indywidualistyczna, wykazywali niższy poziom zaangażowania niż Hindusi. Autorzy podsumowali badanie, wskazując, że wyższy poziom wspólnotowości powoduje, że wymiana między pracownikiem i organizacją nie jest ograniczona do czysto transakcyjnej. Jak przyznają sami badacze, poziom wymiaru indywidualizm/ wspólnotowość dobrze służy do przewidzenia zaangażowania i wysiłków pracowników, jednakże zaobserwowany związek jest przeciwny do spodziewanego (zgodnie $\mathrm{z}$ tradycyjnym postrzeganiem indywidualizmu jako cechy przyspieszającej rozwój ekonomiczny). Wnioskiem z tych badań jest stwierdzenie, że większe starania pracowników mogą przyczyniać się do osiągnięcia wyższego poziomu produktywności. 
Warto zauważyć, że wpływ analizowanego w pracy wymiaru kultury nie ogranicza się do wzrostu efektywności pracowników. Zgodnie z analizą Knacka i Keefera (1997) wysoki poziom wspólnotowości wiąże się z notowaniem wyższego poziomu lojalności w stosunku do grupy. Dzięki temu mniej prawdopodobne jest napotkanie zachowań kontrproduktywnych wymierzonych w kooperanta lub firmę, w której zatrudniony jest pracownik.

Wyższy poziom zaufania pozwala ograniczyć sformalizowanie i biurokrację gospodarki. Dzięki działaniu banku usług (ang. favour bank), przypominającego ten z powieści The Bonfire of the Vanities (Putnam 2013), część transakcji może opierać się na zaufaniu. Niesformalizowanie, jak można przypuszczać, umożliwia większą elastyczność gospodarki, której potrzeba jest szczególnie widoczna w czasach kryzysu.

Ketkar et al. (2012) na podstawie analizy danych ankietowych stwierdzili, że w społeczeństwach zorientowanych wspólnotowo większość partnerów handlowych uważa, że ich relacja biznesowa nie ma charakteru wyłącznie transakcyjnego, lecz, że kupiec i sprzedawca tworzą grupę. $Z$ pewnością jest to przewaga tej kultury w stosunku do społeczeństwa indywidualistycznego, charakteryzującego się transakcyjnym podejściem do relacji biznesowych. Po pierwsze, częściej obserwuje się tu bezpośrednią komunikację (ang. face to face), co stymuluje zaangażowanie stron w dokonanie i wypełnienie warunków transakcji. Dla przykładu, w społeczeństwach zorientowanych wspólnotowo częściej obserwuje się zaangażowanie producentów $\mathrm{w}$ proces produkcji. Po drugie, zaufanie partnerów transakcji przyczynia się do wytworzenia przewagi konkurencyjnej. W związku z postrzeganiem partnera handlowego jako członka grupy, w stosunku do którego jest się lojalnym, w społeczeństwach zorientowanych wspólnotowo, jak można przypuszczać, relacje kontraktowe są trwalsze, a partnerzy handlowi mogą pokładać w sobie większe zaufanie, co pozwala obniżyć koszty transakcyjne.

Do takich samych wniosków dochodzą Knack i Keefer (1997). Na podstawie analizy opartej na założeniach teorii równowagi ogólnej badacze wskazują, że wyższy poziom zaufania w społeczeństwie prowadzi do wyższego odsetka dochodu przeznaczanego na inwestycje i szybszego wzrostu gospodarczego.

Ponadto, relacje biznesowe są trwalsze w krajach o wyższym poziomie orientacji na wspólnoty. Prawdopodobnie wynika to z ich (często) nieformalnego charakteru. Biznesmeni wywodzący się z takich kultur nie wbudowują w kontrakty tzw. klauzul rozwodowych (ang. divorce clauses). Takie zachowanie oznacza, że menedżerowie nie zakładają zakończenia współpracy biznesowej w czasie podpisywania kontraktu (Tiessen 1997).

Podsumowując powyższe rozważania na temat wpływu efektywnych relacji między podmiotami gospodarczymi na wzrost gospodarczy, można przywołać zdanie Tiessena (1997), który na podstawie przeglądu literatury stwierdza, że efekty wykorzystania zasobów zależą od efektywności relacji, którą obserwuje się w społecznościach zorientowanych wspólnotowo. 
Jednakże w literaturze przedmiotu pojawiają się głosy wskazujące na fakt, że osoby żyjące w kulturach zorientowanych wspólnotowo wykazują wyższy poziom zaufania i dbają o długotrwałe utrzymywanie relacji z członkami tej samej grupy. Natomiast osoby postrzegane jako nienależące do grupy traktowane są z większą rezerwą. Zgodnie z badaniami przeprowadzonymi przez Huffa i Kelley (2005) menedżerowie pochodzący ze Stanów Zjednoczonych są bardziej ufni i wykazują silniejszą orientację na klienta niż kierownicy wychowani w kulturze azjatyckiej. Takie empiryczne obserwacje mogą przemawiać za potrzebą traktowania wspólnotowości jako wielorodnego konstruktu i podkreślają potrzebę dalszych badań na temat wpływu kultury na wzrost gospodarczy. Niższy poziom ufności wyjaśnia pojęcie wspólnotowości grupowej (ang. in-group collectivism) zaproponowane przez House et al. (2004).

\subsection{Redukcja częstości zachowań egoistycznych}

Drugim mechanizmem oddziaływania orientacji społeczeństwa na skali indywidualizm-wspólnotowość na wzrost gospodarczy jest ograniczenie zachowań egoistycznych. Zgodnie z omówioną w pierwszym rozdziale definicją zaproponowaną przez Chen i Westa (2008) wysoki poziom wspólnotowości wiąże się z poczuciem połączenia i jedności z innymi oraz orientacją raczej na relacje niż transakcje.

Na podstawie definicji zaproponowanej przez amerykańskich psychologów (Chen, West 2008) można przypuszczać, że w społeczeństwach, w których poziom orientacji wspólnoty jest wysoki, aktorzy ekonomiczni będą przejawiać empatię oraz chęć zachowania się zgodnie z ważnymi dla tego społeczeństwa normami etycznymi. Dalej przedstawiono wnioski z kilku badań, które świadczą o wpływie takich zachowań na tempo rozwoju ekonomicznego.

Za prawdziwością definicji wspólnotowości zaproponowanej przez autorów Measuring individualism and collectivism: The importance of considering differential components, reference groups, and measurement invariance przemawia stwierdzenie Tiessena (1997): „ludzie o orientacji wspólnotowej uważają się za współzależnych członków grupy"1.

Adams i Ruiz-Ulloa (2003) wskazują na podstawie przeprowadzonego case study, że wysoki poziom indywidualizmu w społeczeństwie może wpływać na pojawienie się problemów w komunikacji interpersonalnej. Brak porozumienia jest powodowany nierównością celów indywiduum i grupy. W związku z tym wyższy poziom orientacji na wspólnoty może przyczynić się do wzrostu tempa rozwoju gospodarczego dzięki utożsamieniu się jednostek z grupą i polepszeniu współpracy.

${ }^{1}$ Ang. "Collectivists perceive themselves as interdependent members of an in group" (podkreślenie J.H. Tiessena).

Ekonomia - Wroclaw Economic Review 22/1 (2016)

(C) for this edition by CNS 
Ograniczenie zachowań egoistycznych poprzez wzrost poziomu orientacji na wspólnoty zostało potwierdzone w kilku badaniach statystycznych. Cobb (1976) oraz Naroll (1983) zaobserwowali istnienie związku statystycznego, zgodnie z którym w krajach, gdzie notuje się większy poziom indywidualizmu, jednocześnie występuje wyższy poziom przestępczości. Na marginesie warto zauważyć, że wzrost poziomu przestępczości niekoniecznie wiąże się — ceteris paribus — ze spadkiem tempa wzrostu PKB, jednakże z pewnością nie przyczynia się do rozwoju ekonomicznego sensu largo.

Również Coleman (1990) wskazuje na istnienie powyższego związku. Badacz konkluduje swój artykuł, stwierdzając, że normy grupowe ograniczają zachowania samowolne, dzięki czemu jednostki wnoszą wkład do społeczeństwa. Dzięki istnieniu wewnętrznych i zewnętrznych sankcji w przypadku zachowań samolubnych w sytuacjach, kiedy optymalizacja własnych zysków prowadzi do nieoptymalnego z punktu widzenia ogółu wyniku, społeczeństwa zorientowane wspólnotowo będą dokonywać efektywniejszych wyborów.

O prawdziwości powyższego rozumowania świadczy komparatywne badanie przeprowadzone przez Huffa i Kelley (2005). Na podstawie analizy wpływu poziomu orientacji na wspólnoty na konkurencyjność w dwóch amerykańskich stanach i sześciu krajach azjatyckich, stwierdzają: „prawdopodobieństwo, że osoba zorientowana wspólnotowo zaangażuje się w nieetyczne zachowanie jest niskie, ponieważ ludzie są przywiązani do grupowych wartości i wierzeń oraz dążą do osiągnięcia interesu grupy" ${ }^{\prime 2}$ Z drugiej strony, niektórzy badacze wskazują na kontrproduktywne wpływy potrzeby przynależności do grupy; m.in. stwierdza tak McClelland (1976), wskazując, że jest ona przeciwieństwem do orientacji na osiągnięcia i odwraca ludzi od efektywności i chęci osiągnięcia sukcesu.

\subsection{Wzrost poczucia bezpieczeństwa zapewniany przez przynależność grupową}

Przynależność do wspólnoty nie tylko powoduje narzucenie jednostce norm zachowań, lecz także zapewnia pomoc w sytuacjach kryzysowych. Zgodnie z badaniami Knacka i Keefera (1997) jedną z cech społeczeństwa wspólnotowego jest istnienie solidarności grupowej, która wyraża się m.in. dzieleniem się zarówno obowiązkami, jak też przywilejami.

Interpersonalna solidarność w kulturach wspólnotowych wyraża się m.in. w pomaganiu innym w znalezieniu i utrzymaniu pracy. Jak zaobserwowali Gomez-Mejia i Wellbourne (1991), średnia długość czasu pracy w jednym przedsiębiorstwie różni się pomiędzy krajami i jest silnie skorelowana z poziomem indywidualizmu i wspólnotowości.

2 Ang.: ,The likelihood that collectivists will engage in opportunistic behavior is low because people hold group values and beliefs and seek collective interests". 
Jednakże współodczuwanie problemów innych członków społeczeństwa, które wynika z poczucia jedności z innymi, nie kończy się na niesieniu pomocy wyłącznie w sytuacjach, w których to udzielenie wsparcia nie generuje kosztów, lecz także, gdy pomagający musi podzielić się tym, co ma. Jak zauważył Ball (2001), powyższa cecha społeczeństw zorientowanych wspólnotowo może wpływać na tempo rozwoju gospodarczego, ponieważ — jak można przypuszczać - redystrybucja prowadzona przez społeczność, wspólnotę charakteryzuje się niższym kosztem niż ta zorganizowana przez instytucje państwa.

Tradycyjne więzi społeczne, silniejsze w społeczeństwach wspólnotowych, oferują nieformalne ubezpieczenie na wypadek niefortunnych wydarzeń w życiu jednostki, takich jak: choroba, utrata pracy czy pożar. Dzięki większemu poczuciu bezpieczeństwa jednostki są bardziej skłonne do podejmowania ryzyka, z jakim wiąże się założenie przedsiębiorstwa oraz inwestowanie.

Ponadto, silne i aktywne wspólnoty przejmują część obowiązków, które w nowoczesnych państwach kapitalistycznych wypełnia państwo. Dla przykła$\mathrm{du}$, opieka nad osobami starszymi, ubezpieczenie od bezrobocia oraz na wypadek choroby są — w społeczeństwach silnie wspólnotowych — realizowane przez rodziny oraz wspólnoty lokalne. Analiza krajów Europy Zachodniej pozwala stwierdzić istnienie korelacyjnego związku pomiędzy nasileniem analizowanego w pracy wymiaru kultury a wielkością wydatków społecznych państwa.

Warto zwrócić uwagę, że część badaczy wskazuje również na istnienie odwrotnej zależności, przypuszczając, że wzrost gospodarczy powoduje większe zorientowanie kultury na grupę. Prawdopodobnie pierwszym autorem, który sformułował powyższy wniosek, był Kuznets (1955: 21). Przesłanką do takiego przypuszczenia była obserwacja, że im kraj jest bogatszy, tym bardziej redystrybucyjną politykę prowadzi. Jednakże, w świetle powyższej argumentacji, większe wydatki państwa na opiekę społeczną świadczą raczej o większym indywidualizmie: państwo przejmuje zadania realizowane tradycyjnie przez wspólnoty.

Wniosek o występowaniu dwukierunkowej zależności pomiędzy wzrostem gospodarczym a zorientowaniem na indywiduum/wspólnoty został również sformułowany na podstawie przeglądu literatury przez Balla (2001), który zauważył, że nie tylko orientacja na wspólnoty przyspiesza wzrost gospodarczy, lecz także wyższy poziom bogactwa przyczynia się zmiany orientacji analizowanego wymiaru kultury na bardziej indywidualistyczną.

$\mathrm{Za}$ istnieniem takiej relacji przemawiają również inne argumenty. Yankelovich (1994) stwierdza na podstawie analizy wielu badań ankietowych przeprowadzonych w Stanach Zjednoczonych w ciągu XX wieku, że w ostatnich kilkudziesięciu latach możliwa jest do zaobserwowania zmiana orientacji z wartości wspólnotowych na wartości rynkowe (tj. indywidualistyczne). Również Putnam (2000) zauważył spadek zaangażowania społecznego w ostatnich kilkudziesięciu latach. 


\subsection{Pozytywny wpływ na innowacyjność}

Tradycyjnie przyjmowało się, że wyższy poziom indywidualizmu, który łączy się z takimi cechami, jak samodzielność i wyjątkowość oraz chęć osiągnięć, sprzyja odnotowywaniu dużej liczby innowacyjnych pomysłów, produktów i usług. Zdroworozsądkowa zależność pomiędzy innowacyjnością i analizowanym w pracy wymiarem kultury charakteryzuje się przeciwnym kierunkiem niż ten, za którym opowiadają się współcześni badacze. Pomimo że ekonomiści uważali do niedawna, że to wolny rynek i uznanie dla wartości indywidualistycznych pobudza przedsiębiorczość i indywidualizm, Rosenbusch et al. (2011) jednoznacznie stwierdzają, że wspólnotowość pozytywnie wpływa na innowacje.

W jaki sposób przejawy uznania dla wartości wspólnotowych przyczyniają się do notowania w gospodarce wyższego poziomu innowacyjności? Hurley (1995) stwierdza, że otrzymywane przez ludzi wsparcie oraz współpraca, a przede wszystkim możliwość uzyskania pomocy są pozytywnie powiązane z innowacyjnością.

W celu zrozumienia mechanizmu łączącego zorientowanie na wspólnoty z innowacyjnością gospodarki, Power et al. (2010) wyróżniają dwa typy inwestycji:

1. W strukturę (ang. asset frontier/structure), której celem jest kupno aktywów materialnych lub kapitałowych;

2. w infrastrukturę (ang. operating frontier/infrastructure), tj. w kapitał ludzki, reorganizację procesu produkcji oraz wiedzę na jego temat.

Zgodnie z wynikami komparatywnego badania rozwijających się krajów Azji i wysoko uprzemysłowionych krajów Zachodu (Power et al. 2010), kraje charakteryzujące się wysokim poziomem orientacji na wspólnoty cechuje jednocześnie wyższy poziom inwestycji w infrastrukturę. Jednocześnie dzięki omówionym powyżej zyskom ze współpracy stopa zwrotu z tego typu inwestycji jest wyższa w gospodarkach tworzonych przez społeczeństwa wspólnotowe.

Inną istotną różnicą pomiędzy krajami zorientowanymi na wspólnotę a tymi zorientowanymi na jednostkę jest, że w tych pierwszych większy nacisk kładzie się na innowacje procesowe (Vecchi i Brennan 2009). Możliwym wythumaczeniem jest odwołanie się do chęci wyróżnienia się i wyjątkowości, które nieodzownie łączą się z indywidualizmem (Green et al. 2005). Powyższe potrzeby, jak można przypuszczać, motywują ludzi do zakupu nowych, wyróżniających się dóbr. $Z$ drugiej strony, jednostki zorientowane wspólnotowo, odczuwając jedność z innymi ludźmi i identyfikując się z grupą, preferują zakup produktów nieświadczących o ich statusie materialnym. W związku z tym innowacyjność w tych kulturach jest ukierunkowana na obniżenie kosztów produkcji poprzez innowacje procesowe, a nie na dostarczeniu na rynek nowych produktów.

Cerne et al. (2013) odkryli inny związek pomiędzy analizowanym w pracy wymiarem kultury a innowacyjnością. Mianowicie, zgodnie z przeprowadzonymi badaniami ekonometrycznymi, kultury indywidualistyczne bardziej sprzyjają fazie inwencji, natomiast zorientowanie na wspólnoty zwiększa efektywność ko- 
mercjalizacji nowych pomysłów. Warto zwrócić uwagę, że dopiero przeprowadzenie zakończonego sukcesem procesu wprowadzenia innowacji na rynek przyczynia się do rozwoju ekonomicznego.

W literaturze przedmiotu pojawiają się również głosy przeciwne, wskazujące, że prawdziwa jest odwrotna zależność, tj. wyższy poziom indywidualizmu wspiera rozwój innowacyjności. Jednakże wydaje się, że jest to nieuprawniony wniosek. Dla przykładu, Taylor i Wilson (2012) konkludują swoje badania stwierdzeniem, że indywidualizm pozytywnie wpływa na poziom innowacyjności. Jednakże badacze usiłujący odpowiedzieć na pytanie, czy Kultura wciąż jest ważna? ${ }^{3}$ popełnili istotny błąd, używając jako zmiennej endogenicznej liczby patentów zamiast liczby wdrożonych innowacji.

Zgodnie z przytoczoną tu argumentacją można wyjaśnić otrzymane przez Taylora i Wilsona (2012) wyniki, powołując się na fakt, że indywidualizm rzeczywiście wspiera pierwszą fazę innowacyjności, tj. pomysł, natomiast późniejsze fazy rozwoju innowacji są bardziej efektywne w społeczeństwie zorientowanym wspólnotowo.

Poza omówionymi mechanizmami wpływu kulturowego wymiaru indywidualizm-wspólnotowość na tempo wzrostu gospodarczego niektórzy badacze opowiadają się również za istnieniem odwrotnej zależności. Zgodnie z takim poglądem, nazywanym teorią modernizacji (ang. modernisation theory), wysoki poziom dobrobytu w społeczeństwie powoduje, że ludzie stają się bardziej indywidualistyczni.

Ta teoria jest potwierdzana empirycznie przez zdarzenia ostatnich kilkudziesięciu lat, kiedy to - wraz z wzrostem dobrobytu w Stanach Zjednoczonych i Japonii - wzrósł poziom indywidualizmu w tych społeczeństwach (Hamamura 2011). Również Putnam (2000) pisze, że spadek zaangażowania społecznego w tym okresie jest zauważalny.

\section{Wnioski}

W artykule wskazano cztery potencjalne mechanizmy łączące orientację społeczeństwa na wspólnoty i wzrost gospodarczy: (1) zwiększenie efektywności relacji między podmiotami ekonomicznymi, (2) redukcję częstości zachowań egoistycznych, (3) wzrost poczucia bezpieczeństwa zapewniany przez przynależność grupową oraz (4) pozytywny wpływ na innowacyjność. Na tej podstawie można wyjaśnić obserwacje czynione przez ekonometryków, które wskazują, iż gospodarki krajów, których społeczeństwa wykazują cechy kolektywistyczne, rozwijają się szybciej. Mianowicie, wskazanie mechanizmów uzasadnia wniosek, iż istnieje związek przyczynowy, zgodnie z którym orientacja społeczeństwa na wspólnoty powoduje szybszy rozwój ekonomiczny.

3 Tytuł angielski: Does Culture Still Matter?: The Effects of Individualism on National Innovation Rates. 
$\mathrm{Na}$ podstawie dotychczasowego stanu badań związków pomiędzy zorientowaniem społeczeństwa na wspólnoty a rozwojem ekonomicznym nie można stwierdzić, które z wyróżnionych mechanizmów przyczynowych mają istotny wpływ. Dlatego, opisana powyżej analiza pozwala sformułować wiele problemów badawczych, których rozwiązanie wymagać będzie dalszych badań empirycznych. Po pierwsze, należy na podstawie analiz ekonometrycznych oszacować wpływ każdego z czterech mechanizmów na obserwowany szybszy rozwój krajów, których społeczeństwa wykazują komunitarystyczną orientację. Po drugie, należy prowadzić badania mające na celu wskazanie innych, nieopisanych dotychczas mechanizmów wyjaśniających oddziaływanie analizowanego w artykule wymiaru kultury na rozwój ekonomiczny.

Warto podkreślić, iż badania poświęcone analizie związków pomiędzy zorientowaniem społeczeństwa na wspólnoty a rozwojem ekonomicznym charakteryzują się nie tylko epistemiczną, lecz także praktyczną użytecznością. Biorąc pod uwagę fakt, iż w ciągu ostatnich dziesięcioleci obserwuje się wzrost indywidualizmu społecznego w bogatych krajach Ameryki i Europy, można przypuszczać, iż te gospodarki będą notować niższe wskaźniki tempa rozwoju ekonomicznego. Potwierdzenie obserwacji ekonometrycznych poprzez wskazanie mechanizmów przyczynowych łączących komunitaryzm z bardziej efektywną gospodarką może przekonać polityków ekonomicznych do podjęcia działań zmierzających do przeciwdziałania procesowi pogłębiającego się indywidualizmu społecznego.

\section{Bibliografia}

Adams S., Ruiz-Ulloa B. (2003), An Investigation of Personnel Issues Affecting Kanban Performance: a Case Study, „Engineering Management Journal” 15, nr 4, s. 19-27.

Allik J., Realo A. (2004), Individualism-Collectivism and Social Capital, ,Journal of Cross-Cultural Psychology", Vol. 35, No. 1, s. 29-49.

Ball R. (2001), Individualism, Collectivism, and Economic Development, „The Annals of the American Academy of Political and Social Science" 573, s. 57-84.

Barro R. (1996), Determinants of economic growth: a cross-country empirical study. „National Bureau of Economic Research Working Paper, No. 5698.

Cerne M. et al., (2013), Authentic Leadership, Creativity, and Innovation: A Multilevel Perspective, „Leadership”, Vol. 9, No. 1, s. 63-85.

Chen F., West S. (2008), Measuring Individualism and Collectivism: The Importance of Considering Differental Components, Reference Groups, and Measurement Invariance, ,Journal of Research in Personality" 42, s. 259-294.

Cobb S. (1988), Social Support as a Moderator of Life Stress, „Psychosomatic Medicine” 38, s. 300-314.

Coleman J. et al. (1982), Public and Private Schools, „Society” 19, nr 2, s. 4-9.

Czerniak A. (2012), Wplyw wartości wspólnotowych na stabilność ścieżki wzrostu gospodarczego, [w:] Rozwój gospodarczy a wartości wspólnotowe, red. T. Dołęgowski et al., Warszawa: Wydawnictwo Szkoły Głównej Handlowej w Warszawie.

Diener E. et al. (2000), Similarity of the Relations between Marital Status and Subjective Well-being Across Cultures, „Journal of Cross Cultural Psychology” 31, s. 419-436. 
Dołęgowski T. (2012), Rozwój gospodarczy a wartości wspólnotowe. Między konkurencyjnościq a solidarnościa, [w:] Rozwój gospodarczy a wartości wspólnotowe, red. T. Dołęgowski et al., Warszawa: Wydawnictwo Szkoły Głównej Handlowej.

Gomez-Mejia L., Wellbourne T. (1991), Compensation Strategies in a Global Context, „Human Resource Planning" 14, s. 29-41.

Green E. et al. (2005), Variation of Individualism and Collectivism within and between 20 Countries: A Typological Analysis, „Journal of Cross-Cultural Psychology” 36, nr 3, s. 321-339.

Hamamura T. (2012), Cultures Becoming Individualistic?, „A Cross-Temporal Comparison of Individualism-Collectivism in the United States and Japan” 16, nr 1, s. 3-24.

Hofstede G. (1980), Culture's Consequences, Beverly Hills: Sage Publications.

Hofstede G. (1991), Empirical models of cultural differences, [w:] Contemporary issues in cross-cultural psychology, red. N. Bleichrodt, P. Drenth, Lisse: Swets and Zetlinger Publishers.

House R. et al., (2004), Culture, leadership, and organizations: The GLOBE study of 62 societies. Sage publications, London.

Huff L., Kelley L. (2005), Is Collectivism a Liability? The Impact of Culture on Organizational Trust and Customer Orientation: A Seven-nation Study, „Journal of Business Research” 58, s. $96-102$.

Hurley R. (1995), Group Culture and Its Effect on Innovative Productivity, „Journal of Engineering and Technology Management" 12, 57-75.

Kellner P. (1994), Economic Development, „Sunday Times”, 20 lutego, sekcja 4, s. 4.

Ketkar S., Kock N., Parente R., Verville J. (2012) The Impact of Individualism on Buyer-Suplier Relationship Norms, Trust and Market Performance: An Analysis of Data from Brazil and the USA, „International Business Review” 21, s. 782-793.

Knack S., Keefer Ph. (1997), Does Social Capital Have an Economic Payoff? „The Quarterly Journal of Economics" 112, nr 4, s. 1251-1288.

Kuznets S. (1955), Economic Growth and Income Inequality, „The American Economic Review” $45, \mathrm{nr} 1, \mathrm{~s} .1-28$.

Marks M. (2004), The Prison as Metaphor: Re-imagining Internaitonal Relations, New York: Peter Lang Publishing.

Maziarz M. (2015), Collectivism and Economic Development - a Causal Analysis, „Socioeconomica - The Scientific Journal for Theory and Practice of Socio-economic Development" 4, nr 8, s. 277-290.

McClolland D. (1976), The Achieving Society, New York: John Wiley and Sons.

Naroll R. (1983), The moral order, Beverly Hills: Sage Publications.

Ostrom E. (1990), Governing the Commons: The Evolution of Institutions for Collective Action, Cambridge: Cambridge University Press.

Peterson R. (1980), Enterpreneurship and Organization, [w:] Handbook of Organisational Design, red. P. Nystrom, W. Starbuck, Oxford: Oxford University Press.

Power S. et al. (2010), The Cultural Characteristic of Individualism/Collectivism: a Comparative Study Implications for Investment in Operations between Emerging Asian and Industrialized Western Countries, „Journal of Operation Management” 28, s. 206-222.

Putnam R. (2013), The Prosperous Community: Social Capital and Public Life, [w:] Cross Currents: Cultures, Communities, Technologies, (251-25), red. K. Blair, R. Murphy, J. Almjeld, New York: Cengage Learning.

Ramamoorthy N. et al. (2007), Individualism-collectivism Orientation and Employee Attitudes: A Comparison of Employees from the High-technology Sector in India and Ireland, „Journal of International Management" 13, s. 187-203.

Rosenbusch N., Brickman J., Bausch A. (2011), Is Innovation Always Beneficial? A Metaanalysis of the Relationship between Innovation and SMEs, ,Journal of Business Venturing” 26, s. 441-457. 
Siewierski J. (2012), Autonomia jednostki a wspólnota. Analiza porównawcza rozwoju gospodarczego na Zachodzie i w Azji Wschodniej, [w:] Rozwój gospodarczy a wartości wspólnotowe, red. T. Dołęgowski et al., Warszawa: Wydawnictwo Szkoły Głównej Handlowej.

Smith A. (2007), An Inquiry into the Nature and Causes of the Wealth of Nations, Metalibri, http:// metalibri.wikidot.com/title:an-inquiry-into-the-nature-and-causes-of-the-wealth-of (dostęp: 22.01.2016).

Swank D. (1996), Culture, Institutions, and Economic Growth: Theory, Recent Evidence, and the Role of Communitatian Polities, „American Journal of Political Science” 40, s. 660-679.

Taylor M., Wilson S. (2012), Does Culture Still Matter?: The Effects of Individualism on National Innovativeness, „Journal of Business Venturing” 27, s. 234-247.

Tiessen J. (1997), Individualism, Collectivism and Enterpreneurship: a Framework for International Comparative Research, „Journal of Business Venturing” 12, s. 367-384.

Vecchi A., Brennan L. (2009), A Cultural Perspective on Innovation in International Manufacturing, ,Research in International Business and Finance” 23, nr 2, s. 181-192.

Wagner J. (2002), Utilitatian and Ontological Variation in Individualism-Collectivism, „Research in Organizational Behavior" 24, s. 301-345.

Yankelowich D. (1994), How Changes in the Economy are Reshaping American Values, „Values and Public Policy" 4, nr 1, s. 16-53.

Ekonomia - Wroclaw Economic Review 22/1 (2016)

(C) for this edition by CNS 